\title{
Produção e desenvolvimento de colônias de abelhas africanizadas (Apis mellifera l.) a partir de diferentes áreas e idades de cria
}

\author{
Production and development of africanized honey bee (Apis mellifera 1 .) colonies departing from \\ different comb brood areas and brood ages
}

\author{
Roberto Henrique Dias da Silva ${ }^{1}$ Breno Magalhães Freitas ${ }^{2,3}$
}

\section{RESUMO}

A apicultura brasileira usa da captura de enxames silvestres de abelhas melíferas africanizadas (Apis mellifera L.) para repor elou aumentar o número de colônias dos apiários, possuindo inconvenientes como a dependência da natureza para captura dos enxames, a heterogeneidade genética das colonias capturadas e a possibilidade desses enxames serem portadores de doenças e parasitas prejudiciais à sanidade das abelhas. $O$ presente trabalho testa e apresenta uma técnica de divisão de colônias de abelhas melíferas africanizadas para a produção de novas colonias fortes em curto espaço de tempo, a partir de recursos mínimos de cera, cria e alimento. Os resultados mostraram que núcleos de A. mellifera formados inicialmente com uma rainha jovem e fecundada, $1 \mathrm{~kg}$ de operárias, um quadro de cria fechada, um quadro de favo puxado e vazio e dois quadros com cera alveolada permitem a produção de novas colônias em 42 dias. Portanto, pode-se concluir que a técnica de divisão de colônias por formação de núcleos como descrito acima, oferece aos apicultores uma alternativa viável para a produção $e$ comercialização em larga escala de novas colônias de abelhas melíferas africanizadas.

Palavras-chave: espaço para postura, divisão de colônias, formação de núcleos, recursos mínimos.

\section{ABSTRACT}

The Brazilian apiculture relies upon collecting wild swarms of Africanized honey bees (Apis mellifera L.) to replace and/or increase the number of colonies in the apiaries. This practice brings problems such as dependence on nature to capture any swarm, diverse genetic make-up of the colonies captured and the possibility of these swarms be carrying diseases and parasites harmful to the bees. The present work tests and presents a technique to split colonies of Africanized honey bees to produce new strong colonies in short time, departing from little resources of wax, brood and food stores. Results showed that A. mellifera nuclei formed by a young and mated queen, $1 \mathrm{~kg}$ of workers, a frame of sealed brood, an empty frame of drawn beeswax and two frames containing an embossed sheet of beeswax each, allows producing new colonies within 42 days. Therefore, it is concluded that the technique to split colonies in nuclei as described above gives beekeepers a viable alternative to produce and commercialize new colonies of Africanized honey bees in large scale.

Key words: colony splitting, space for laying eggs, minimal resources, nuclei formation.

\section{INTRODUÇÃO}

O crescimento da apicultura no Brasil tem levado a aumentos na procura por novas colônias de abelhas melíferas (Apis mellifera L.), gerando escassez de famílias com bom potencial genético e sanitário, haja vista que a atividade apícola tradicional baseia-se na captura de enxames silvestres (VIEIRA, 1986; LEOPOLDINO et al., 2002). Essa prática, usada para repor e/ou aumentar o número de colônias dos apiários, possui inconveniências como a dependência da natureza para captura dos enxames, a heterogeneidade genética das colônias capturadas e a possibilidade desses enxames serem portadores de doenças e parasitas prejudiciais à sanidade das abelhas, todos fatores que normalmente afetam significativamente a produtividade das colônias (DUAY, 1996).

Apesar das desvantagens observadas na apicultura baseada em captura de enxames silvestres,

\footnotetext{
${ }^{1}$ Zootecnista, MSc., Diretor Zootécnico Grupo Fazenda Conceição da Barra Ltda (FADA).

${ }^{2}$ Engenheiro Agrônomo, PhD em Apicultura e Polinização, Universidade Federal do Ceará.

${ }^{3}$ Autor para correspondência: Departamento de Zootecnia, Centro de Ciências Agrárias, Universidade Federal do Ceará, CP 12168 Campus do Pici, 60021-970, Fortaleza, CE. E-mail:freitas@ufc.br
} 
ela continua sendo usada pela maioria dos apicultores para compensar a perda de enxames, acarretando também em baixa produtividade nos apiários (DUAY, 1996). Dessa forma, a multiplicação artificial de colônias, técnica utilizada na apicultura com o intuito de preservar e multiplicar qualidades genéticas existentes em um determinado grupo de indivíduos, pode ser usada para assegurar que o potencial produtivo de colônias superiores seja bem aproveitado pelos apicultores criando novas colônias com características semelhantes em seus apiários (WIESE, 1985; SOMMER, 1996; VIEIRA, 1986).

Além disso, a multiplicação artificial e comercialização de colônias de abelhas melíferas podem tornar-se uma boa alternativa de mercado para os apicultores, pois a taxa de sucesso na captura de enxames silvestres vem caindo ano após ano, devido tanto ao aumento no número de colméias a serem povoadas, como à redução das condições favoráveis para a multiplicação natural dos enxames, principalmente com o aumento das áreas desmatadas (FREITAS, 1996; LEOPOLDINO, 2000).

A literatura apresenta muitos métodos de multiplicação de colônias (YORK JR., 1975; KURLETTO, 1980; MENDEZ, 1980; ALMEIDA, 1983; WIESE, 1985; VIEIRA, 1986; MUXFELT, 1987; COUTO, 1993; LENGLER, 1997; LAIDLAW JR., 1998; LENGLER et al., 2000), porém eles geralmente são de difícil execução, demandam muita mão-de-obra, demoram um longo tempo para produzir as novas colônias ou apresentam baixa taxa de sucesso. O presente trabalho testa e apresenta uma técnica de divisão de colônias de abelhas melíferas africanizadas para a produção de novas colônias fortes em um curto espaço de tempo, a partir de recursos mínimos de cera, cria e alimento.

\section{MATERIAL E MÉTODOS}

O trabalho experimental foi conduzido no apiário do Departamento de Zootecnia da Universidade Federal do Ceará, em Fortaleza - CE. Fortaleza é a capital do estado do Ceará, apresentando clima seco e sub-úmido (IPLANCE, 1993), e está localizada na região litorânea, situada entre o baixo sertão e as serras úmidas (NORONHA, 1997).

Vinte e uma colméias populosas, em bom estado sanitário e com reserva de alimento, foram selecionadas no apiário para fornecerem as abelhas adultas, crias e favos para a formação dos núcleos a serem testados. Paralelamente, uma outra colméia em condições semelhante às demais foi preparada para a produção de rainhas, de forma que todas as rainhas dos núcleos que iriam ser formados e testados fossem irmãs, jovens e de idade conhecida, tendo assim as mesmas condições genéticas e potencial reprodutivo. O método utilizado para produzir as rainhas foi a enxertia (LAIDLAW JR., 1998).

Após o nascimento, as 21 novas rainhas foram introduzidas nas 21 colônias previamente selecionadas, e tão logo elas foram aceitas e iniciaram a postura, os núcleos a serem testados foram montados a partir dessas colônias, cada qual recebendo quatro quadros de crias com abelhas aderentes (aproximadamente $1 \mathrm{~kg}$ de operárias) e a jovem rainha fecundada. Sete dias depois de serem formados, os núcleos foram submetidos aos tratamentos. As colméias que forneceram todo o material físico e biológico para montagem dos núcleos receberam novas realeiras para garantirem sua sobrevivência.

Os núcleos foram montados em caixas de papelão reciclado, com capacidade para cinco quadros padrão Langstroth. Todos os tratamentos possuíam sete repetições e os vinte e um núcleos foram distribuídos por sorteio aleatório dentro do apiário: $\mathrm{T}_{1}-\mathrm{Núcleo}$ contendo aproximadamente $1 \mathrm{~kg}$ de abelhas operárias, uma rainha jovem e fecundada, um quadro de cria fechada, um quadro de favo puxado e vazio, dois quadros de cera alveolada e um alimentador tipo cocho; $\mathrm{T}_{2}$ - Núcleo contendo aproximadamente $1 \mathrm{~kg}$ abelhas operárias, uma rainha jovem e fecundada, um quadro de cria fechada, um quadro de cria aberta, dois quadros de cera alveolada e um alimentador tipo cocho; $\mathrm{T}_{3}-$ Núcleo contendo aproximadamente $1 \mathrm{~kg}$ de abelhas operárias, uma rainha jovem e fecundada, dois quadro de cria fechada, dois quadros de cera alveolada e um alimentador tipo cocho.

Todos os núcleos receberam $500 \mathrm{ml}$ de uma alimentação rica em carboidratos solúveis, sendo esta uma solução de água com açúcar na proporção de $2 \mathrm{~kg}$ de açúcar para 1 litro de água, uma vez por semana. Não foi necessário alimentar com substitutivo de pólen devido à grande oferta desse alimento no campo durante o período do experimento, constatado pela constante chegada de campeiras com pólen nas colônias.

A coleta de dados foi feita a cada 14 dias a partir da montagem dos núcleos. Para tanto, os dois lados de cada quadro tinham suas áreas de cria aberta e fechada (operculada) de operárias e zangões e reserva de alimento, transcritas para folhas de transparência usando-se caneta própria para escrever neste material. Essas áreas foram medidas no escritório do apiário, utilizando-se uma cartolina demarcada com a área de um quadro de ninho e dividido em pequenos quadrados com áreas de 4cm², segundo AL-TIKRITY et.al. (1971). 
Em seguida, foi contado o número de quadradinhos que cada área representava, determinando assim a área analisada. Esta análise foi feita até o desenvolvimento total dos núcleos que se deu quando estas apresentaram um tamanho adequado para serem transferidas para um ninho padrão Langstroth, estando assim em condições de serem comercializadas ou exploradas pelo apicultor de uma forma racional e econômica.

Este ponto de desenvolvimento se deu quando os núcleos apresentaram-se com $85 \%$ da área total disponível (quatro quadros de ninho) utilizada com crias e alimento, e população adulta compatível com esse nível de desenvolvimento. O experimento foi encerrado 70 dias após seu início.

A análise dos dados relativos ao desenvolvimento da área ocupada (cria e alimento) pela colônia foi feita por Análise de Variância, e as médias foram comparadas a posteriori pelo teste de Tukey. O tempo mínimo necessário para o desenvolvimento dos núcleos foi estimado pelo procedimento PROC LIFEREG (SAS, 2000).

\section{RESULTADOS}

As análises de variância realizadas com as áreas totais de cria e alimento mostraram que no início do experimento havia uma diferença significativa $\left(\mathrm{F}_{2,18}=7,98, \mathrm{P}<0,05\right)$ nesse parâmetro estudado entre os tratamentos (Tabela 1). O tratamento com um quadro de cria aberta e um de cria fechada $\left(\mathrm{T}_{2}\right)$ apresentava a maior área ocupada e diferia significativamente do tratamento com um quadro de cria fechada e um de cera puxada $\left(\mathrm{T}_{1}\right)$, que possuía a menor área total dos três tratamentos. O tratamento com dois quadros de cria fechada $\left(\mathrm{T}_{3}\right)$ não diferia significativamente de $\mathrm{T}_{1}$ e $\mathrm{T}_{2}$ (Tabela 1). Essas diferenças eram esperadas, uma vez que os tratamentos foram montados com quantidades diferentes de cria e alimento.
Os dados coletados 14 dias após mostraram por meio da análise de variância, já não haver mais diferenças significativas $\left(\mathrm{F}_{2,18}=1,75, \mathrm{P}>0,05\right)$ entre os três tratamentos (Tabela 1), tendo esse padrão mantido-se constante até o final do experimento aos 70 dias (TABELA 1). Os núcleos foram considerados prontos para comercialização quando $85 \%$ do espaço disponível estavam ocupados com cria e alimento, o que corresponderia a uma área de $4.675 \mathrm{~cm}^{2}$ por núcleo. Valor médio estatístico equivalente a esse $(4.632,0 \pm 404,43)$ foi apresentado pelo $T_{1}$ aos 42 dias de experimento, apesar de ser o tratamento que iniciou o experimento com a menor área total ocupada (Tabela 1). Esse resultado está de acordo com a estimativa feita pelo procedimento PROC LIFEREG (SAS, 1996), que apontou 42,98 dias como o tempo necessário para que os núcleos do tratamento $T_{1}$ atingissem o ponto de comercialização. O tratamento $\mathrm{T}_{3}$ apenas atingiu a taxa média de ocupação ideal após 56 dias de experimento, e o $\mathrm{T}_{2}$ não chegou a esses valores até os 70 dias, quando o experimento foi encerrado (Tabela 1).

\section{DISCUSSÃO}

Os resultados mostraram que o tratamento $\mathrm{T}_{1}$ foi superior aos demais. Além de ter sido o primeiro a atingir a ocupação média de $85 \%$ do espaço disponível na caixa ainda por volta dos 42 dias (Tabela 1), necessita de menor investimento inicial de crias na formação das colônias possibilitando ao criador produzir mais núcleos a partir da mesma matriz. Somase a isso, o fato de que a velocidade de ocupação das áreas disponíveis nas caixas foi reduzida acentuadamente após os 42 dias, demonstrando ser esse o momento ideal de transferir as colônias para caixas de tamanho padrão. Finalmente, $\mathrm{T}_{1}$ eliminou a diferença estatística que o separava de $\mathrm{T}_{2}$ já a partir do $14^{\circ}$ dia do experimento.

Segundo KERR (1949), a postura da rainha depende não somente dela própria, mas também da

Tabela 1 - Médias das áreas totais de cria e alimento $\left(\mathrm{cm}^{2}\right)$ de abelhas africanizadas ( Apis mellifera L.) desenvolvidas em caixas de papelão reciclado.

\begin{tabular}{|c|c|c|c|c|c|c|}
\hline TRAT & 0 & 14 & 28 & 42 & 56 & 70 \\
\hline 01 & $1060,00^{\mathrm{b}} \pm 78,73$ & $3525,85^{\mathrm{a}} \pm 501,71$ & $4272,00^{\mathrm{a}} \pm 480,72$ & $4632,00^{\mathrm{a}} \pm 404,43$ & $4904,00^{\mathrm{a}} \pm 242,12$ & $4991,42^{\mathrm{a}} \pm 196,87$ \\
\hline 02 & $1962,28^{\mathrm{a}} \pm 237,84$ & $2412,57^{\mathrm{a}} \pm 244,24$ & $2897,14^{\mathrm{a}} \pm 352,04$ & $3708,00^{\mathrm{a}} \pm 414,50$ & $3777,14^{\mathrm{a}} \pm 423,03$ & $4176,00^{\mathrm{a}} \pm 445,00$ \\
\hline 03 & $1596,00^{\mathrm{ab}} \pm 122,01$ & $2848,57^{\mathrm{a}} \pm 479,19$ & $3556,00^{\mathrm{a}} \pm 380,85$ & $4185,14^{\mathrm{a}} \pm 382,92$ & $4347,42^{\mathrm{a}} \pm 343,63$ & $4752,57^{\mathrm{a}} \pm 250,60$ \\
\hline
\end{tabular}

Médias seguidas de letras minúsculas iguais na coluna não diferem estatisticamente, $\mathrm{P}<0,05$ (Teste de Tukey).

Ciência Rural, v.34, n.2, mar-abr, 2004. 
quantidade de operárias para alimentação das larvas e construção de alvéolos. Isso pode explicar o rápido crescimento da área ocupada demonstrado por $\mathrm{T}_{1} \mathrm{e}$ $\mathrm{T}_{3}$, haja vista que o primeiro iniciou apenas com um quadro com cria fechada e outro de cera puxada, enquanto o segundo começou com dois quadros com cria fechada. Em ambos os casos, haveria um considerável número de operárias disponíveis para cuidar das crias jovens. No caso de $\mathrm{T}_{1}$, havia também espaço livre para a postura, e esse começou a surgir em $\mathrm{T}_{3}$ à medida que a cria fechada emergia como adulta. $\mathrm{OT}_{2}$, com um quadro ocupado com cria aberta e outro com cria fechada, não possuía grandes áreas disponíveis para postura nem população de operárias para cuidar das novas crias, uma vez que ainda tinham cria aberta para atender, e não pôde acompanhar o ritmo de crescimento dos outros tratamentos. Como as operárias usam a estratégia de transferir informações dentro do ninho a respeito das condições e necessidades da colônia, elas rapidamente determinam as atividades prioritárias ao desenvolvimento da família a cada instante e passam a executá-las (WINSTON, 1987). Dessa forma, o uso de uma quantidade de cria aberta proporcionalmente grande na formação das colônias $\mathrm{T}_{2}$, definitivamente determinou o desenvolvimento mais lento das famílias desse tratamento.

O rápido crescimento dos núcleos observados neste trabalho está de acordo com observações de outros pesquisadores, que apresentam as abelhas africanizadas como uma sociedade bem adaptada para produzir grandes populações em curto espaço de tempo, bastando para isso que haja um bom fluxo de alimento e espaço disponível para o desenvolvimento da colônia (WINSTON 1991; COUTO 1993; SOUSA 1998), condições ofertadas na presente investigação.

\section{CONCLUSÃO}

O presente trabalho permite concluir que é possível produzir novas colônias de $\boldsymbol{A}$. mellifera em curto espaço de tempo, a partir da divisão de famílias fortes, por meio da formação de núcleos com uma adequada proporção de área e idade da cria, espaço para postura e para desenvolvimento da colônia, e assegurando-se acomodação, nutrição, sanidade e proteção contra inimigos naturais adequadas para as abelhas.

Conclui-se também que o desenvolvimento dos núcleos de $\boldsymbol{A}$. mellifera não é proporcional ao tamanho da área inicial de cria. A idade das crias e a disponibilidade de espaço para postura da rainha desempenham papel mais relevante na velocidade com a qual os núcleos alcançam o tamanho ideal para comercialização. Finalmente, a técnica de divisão de colônias por formação de núcleos apresentada e testada neste trabalho oferece aos apicultores uma alternativa viável para a produção e comercialização em larga escala de novas colônias de abelhas melíferas africanizadas.

\section{REFERÊNCIAS BIBLIOGRÁFICAS}

ALMEIDA, J.E.C. Abelhas: manual prático do apicultor. 4.ed. Lisboa : Narciso Correia, 1983. 158p.

AL-TIKRITY, W.S. et.al. A new instrument for brood measurement in a honey bee colony. American Bee Journal, Hamilton, v.111, n.1, p.20-26, 1971.

COUTO, L.A. Estudo do desenvolvimento de colônias formadas artificialmente a partir do uso de pacotes de abelhas africanizadas, européias e F1 (africanizadas x européia), sob diferentes condições ambientais. 1993. 103f. Tese (Doutorado em Ciências) - Curso de Pós-graduação em Genética, Faculdade de Medicina de Ribeirão Preto, USP.

DUAY, P. Manejo para aumento da produtividade. In: CONGRESSO BRASILEIRO DE APICULTURA, 11., 1996, Teresina, PI. Anais... Teresina : Confederação Brasileira de Apicultura, 1996. V.1, 434p. p.121-124.

FREITAS, B.M. Caracterização e fluxo de néctar e pólen na caatinga do nordeste. In: CONGRESSO BRASILEIRO DE APICUlTURA, 11., 1996, Teresina, PI. Anais... Teresina: Confederação Brasileira de Apicultura, 1996. V.1, 434p. p.181185.

IPLANCE. Anuário Estatístico do Ceará. Fortaleza : SEPLAN, 1993. V.3.

KERR, W.E. Algumas comparações entre a abelha européia (Apis mellifera L.) e as abelhas nativas brasileiras (Meliponini). O solo, Piracicaba, p.391, out, 1949.

KURLETO, S. Novo método de formação de núcleo. In: CONGRESSO LATINO-ÍBERO-AMERICANO DE APICUltURA, 3., 1980, Viçosa, MG. Anais... Viçosa : [s.n.], 1980. p.293-294.

LAIDLAW JR. H.H. Criação contemporânea de rainhas. Traduzido por Carlos Alberto Osowski. Canoas : La Salle, 1998. 219 p.

LENGLER, S. Criação racional de abelhas. Santa Maria : [s.n.], 1997. 52p.

LENGLER, S. et al. Efeitos da alimentação energética, açúcar invertido e energética-protéica, açúcares e farinha láctea, no desenvolvimento e produção de mel em núcleos de abelhas africanizadas. Mensagem Doce, São Paulo, n.55, p.20-23, 2000 .

LEOPOLDINO, M.N. Avaliação da eficiência do uso do capim santo (Cymbopogon citratus Stapf.) e feromônio de Nasanov sintético na captura de enxames de Apis mellifera em caixas- 
isca. 2000. 29f. Monografia (Graduação em Agronomia) - Curso de Agronomia, Universidade Federal do Ceará.

LEOPOLDINO, M.N. et al. Avaliação do feromônio de Nasanov sintético e óleo essencial de capim santo (Cymbopogon citratus) como atrativos para enxames de abelhas africanizadas (Apis mellifera). Ciência Animal, Fortaleza, v.12, n.1, p.19-23. 2002.

MENDEZ, F.V. Técnica para hascer núcleos sin buscar la reina. In: CONGRESSO BRASILEIRO DE APICULTURA, 5., 1980, Viçosa, MG. Anais... Viçosa : [s.n.], 1980. p.295-298.

MUXFELT, H. Apicultura para todos. 6.ed. Porto Alegre Sulina, 1987. 242p.

NORONHA, P.R.G. Caracterização de méis cearenses produzidos por abelhas africanizadas: parâmetros químicos, composição botânica e colorimetria. 1997. 147f. Dissertação (Mestrado em Zootecnia) - Curso de Pós-graduação em Zootecnia, Universidade Federal do Ceará.

SAS INSTITUTE INC. SAS/STAT. User's guide, release 6.11.ed. Cary, 1996.

SOMMER, P.G. Seleção e melhoramento de abelhas. In: CONGRESSO BRASILEIRO DE APICULTURA, 11., 1996,
Teresina, PI. Anais... Teresina : Confederação Brasileira de Apicultura, 1996. V.1, 434p. p.77-79.

SOUSA, R.M. Ciclo anual das abelhas africanizadas (Apis mellifera L.) silvestres na caatinga cearense. 1998. 72f. Dissertação (Mestrado em Zootecnia) - Curso de Pós-graduação em Zootecnia, Universidade Federal do Ceará.

VIEIRA, M.F. Apicultura atual. São Paulo : Nobel, 1986. 136p.

WIESE, H. Nova apicultura. 6.ed. Porto Alegre : Agropecuária, 1985. 493p.

WINSTON, M.L. The biology of the honey bee. London, England : Harvard University, 1987. 281p.

WINSTON, M.L. The inside story: internal colony dynamics of Africanized bees. In: SPIVAK, M.; FLETCHER, D.J.C.; BREED, M.D. (ed). The African honey bee. San Francisco, USA : Westview, 1991. p. 201-213.

YORK JR., H.F. Producción de reinas y abejas para la venta en paquetes. In: DADANT, C.C. (Ed). La colmena y la abeja melífera. Montevideo : Hemisferio Sur, 1975. p.733-740. 